$\mathrm{BFJ}$

123,13

490

Received 29 January 2021

Revised 27 May 2021

5 August 2021

Accepted 10 September 2021

\section{Why are geographical indications unevenly distributed over Europe?}

\author{
Sofie Joosse \\ Department of Urban and Rural Development, \\ Swedish University of Agricultural Sciences, Uppsala, Sweden \\ Pepijn Olders \\ Department of Social and Economic Geography, Uppsala University, \\ Uppsala, Sweden, and \\ Wiebren J. Boonstra \\ Department of Earth Sciences, Uppsala University, Uppsala, Sweden
}

\begin{abstract}
Purpose - Through geographical indications, the European Union aims to stimulate economies, especially in lagging rural regions, and to help consumers recognise and locate quality products from specific regions. The highly uneven distribution of geographical indications, and with that the unequal benefits of this policy, have been identified and discussed in the scientific literature on food and rural development.

Design/methodology/approach - Using a statistical analysis of the distribution of geographical indications, the paper tests the validity of several theoretical explanations that are offered in the literature for the uneven spatial distribution.

Findings - From this assessment, the paper concludes, amongst others, that common single-cause explanations for the uneven distribution of labels in Europe have weak explanatory value. Rather, the uneven distribution is based on a complex set of causes, with different effects at national and regional level. Moreover, the findings highlight that in contrast to its aim, the policy does not seem to benefit especially lagging rural regions.

Originality/value - The analysis of the uneven distribution of labels in Europe offered here suggests that a distinction should be drawn between the mechanisms resulting in regional food products versus the mechanisms resulting in regional food labels, such as geographical indications.
\end{abstract}

Keywords Food labels, Geographical indications, Rural development, Spatial distribution Paper type Research paper

\section{Introduction}

The link between food quality and the geography of food has received growing interest during recent decades (Joosse, 2014). The European Union legislation from the 1990s, which introduced labels for the geographical indication of agricultural products (GIs), is part of this development (Krystallis et al., 2017; Quiñones Ruiz et al., 2018; Tarabella et al., 2019). In defining production and consumption standards, regional attributes are used as a quality signal so that specialised products stand out amidst the bulk supply of conventional food

(C) Sofie Joosse, Pepijn Olders and Wiebren J. Boonstra. Published by Emerald Publishing Limited. This article is published under the Creative Commons Attribution (CC BY 4.0) licence. Anyone may reproduce, distribute, translate and create derivative works of this article (for both commercial and noncommercial purposes), subject to full attribution to the original publication and authors. The full terms of this licence may be seen at http://creativecommons.org/licences/by/4.0/legalcode

The authors would like to thank three anonymous reviewers and the journal editor for helpful comments. The authors would also like to thank Jan Amcoff, Danielle van der Burgt, Sofia Cele, Anders Malmberg, Dominic Power, and Susanne Stenbacka for inspiring discussions and valuable suggestions. Sofie Joosse was supported by a FORMAS project Grant (No. 2009-310) and the Tage and Ellen Westin fund. 
products (Bramley and Kirsten, 2007). Roquefort cheese is a good example of how this labelling works: only cheese ripened in the caves close to a small village called Roquefort-surSoulzon in the southern part of France may be named Roquefort.

The justification for GIs relies on the idea that the place of production influences food quality (e.g. Condurso et al., 2016), and that therefore a product typical of a specific place deserves protection against imitations from other places. Through GIs the EU aims to protect products with high quality and good reputation from counterfeits (Josling, 2006; Tarabella et al., 2019).

The economic incentives for GIs are considerable, which is why getting GIs approved can result in a handsome financial benefit for regions and producer cooperatives (Vakoufaris, 2010; Falguera et al., 2012; Borg and Gratzer, 2013; Sellers-Rubio and Más-Ruiz, 2015; Likoudis et al., 2016): the sales-value of labelled products for 2017 is estimated to be 74.8 billion euros (European Commission, 2020b). With GIs the EU intends to increase the profitability of agricultural production and support rural economies, especially in so-called Less Favoured Areas (LFAs) (Tregear et al., 2007, 2015) and so contribute to "retaining the rural population in these areas" (European Commission, 2006, p. 2).

Yet the policy is not justified with economic benefits alone. According to the Council Regulation (European Commission, 2006) labelling aims primarily to help consumers recognise and locate quality products from specific regions. Knowing the origin of a product is important to a growing number of people (Teuber, 2011). Many appreciate the specific characteristics and qualities of regional foods (Krystallis and Ness, 2005; Bernabéu et al., 2011; Aprile et al., 2012; Chamorro et al., 2015), and the transparency about the ethics of production and environmental impact that the certification aims to bring (Dimara and Skuras, 2005; Fandos and Flavián, 2006; Espejal et al., 2008; Falguera et al., 2012; Gracia and de-Magistris, 2016; Grunert and Aachmann, 2016; Tessitore et al., 2020).

While interest in labelled regional food is a Europe-wide trend (Cei et al., 2018; European Commission, 2020b; Sadílek, 2020), GIs are unevenly distributed over the European Union (EU). To substantiate: in 2017 five out of the 28 EU countries reaped $87 \%$ of the value of GIs (European Commission, 2020b). Only some regions in a few countries appear interested and/or capable of successfully establishing GIs. Italy, for example, registered most GIs, with 847 products in 2017, while in the same year Hungary, Slovenia, Bulgaria, Sweden, Romania, Denmark, Croatia, Malta, Slovakia, Belgium, Luxembourg, Finland, Cyprus, Lithuania, Estonia and Latvia together only registered 385 products (European Commission, 2020b). It is relevant to consider these noticeable differences in order to understand the potential of GIs to stimulate rural economies, especially in Less Favoured Areas (LFAs), as intended by the policy.

The scientific literature presents a variety of explanations for the uneven distribution (e.g. Parrott et al., 2002; London Economics, 2008; Sadílek, 2020), but remains inconclusive about the plausibility and relative contribution of the different explanations. Therefore, this paper's aim is to explain the uneven distribution of GIs by testing the strength of the explanations offered in literature.

The paper first describes the EU GI scheme for those readers who are new to the topic (Section 2, Background). Next follows a review of the explanations offered in the literature for the spatial distribution of labels, which are consequently reworked into hypotheses (Section 3, Theoretical framework). The paper then presents a first analysis of the uneven distribution, and highlights the flaws of this analysis to motivate instead a multi-level analysis (Section 4, First analysis). The multi-level methodology and the data and variables used are then outlined (Section 5, Methodology). The results from the multi-level analysis are presented (Section 6, Results) and used to test the validity of three explanations that are offered for the uneven distribution of GIs in the European Union (Section 7). The paper ends with a discussion and conclusion.

Geographical indications unevenly distributed 
BFJ

123,13

492

\section{Background}

The ideas behind GIs are not new. As early as the 1400s France established laws to protect products from specific regions, and in 1935 the French formulated a modern version of these protective laws: the Appellation d'Origine Contrôlée (AOC) system (Trubek and Bowen, 2008). The AOC serves to protect the integrity and quality of wines, and inspired Italy, Portugal and Spain to introduce similar legislation (Ilbery et al., 2005; Moran, 1993a). People in these countries widely accept the idea that a geographical origin of a product is significant for its quality, an idea that is also captured in the concept of "terroir" (Barham, 2003; Trubek, 2008).

Unsurprisingly therefore, France, Spain, Portugal and Italy were the first countries to request, in the late 1980s, the EU to protect product names (Marcoz et al., 2016), while other European countries were more indifferent towards labelling regional products. Nevertheless, in 1992 the EU established the GI scheme (European Commission, 1992). After the WTO agreed with the USA's complaints of disguised trade protection (London Economics, 2008; Josling, 2006), producer groups outside the European Union could also apply.

The GI scheme includes a large variety of regional food products, ranging from food from small-scale artisan production sold in relatively limited markets, to food from large-scale production catering to the global market, and everything in between (IPSOS, 2013; Bonadonna et al., 2017; Krystallis et al., 2017; Tarabella et al., 2019). As many will be already familiar with a regional product that caters to a global market such as Roquefort or Prosciutto di Parma, the next example highlights instead a regional Swedish product with a proximate market:

"Upplandskubb" is a rustic bread, with a colour varying between gingerbread and greyish-brown. The particular qualities of "Upplandskubb" are closely linked with morphological characteristics and climate and soil conditions in the geographical area. Characteristic of "Upplandskubb" is that it is made from rye and wheat from the geographical area [...] The bread is baked by boiling in a cylindrical tin in a water bath. Production must take place in the identified geographical area. The bread is sold sliced lengthwise in quarters. There is a human factor involved in baking "Upplandskubb" according to the special method, which requires good practical knowledge of how best to prepare the dough to suit the raw ingredients and the equipment so as to bring out the special qualities of the bread. (European Commission, 2014)

The above quote is from a PDO (Protected Designation of Origin) application for Upplandskubben. The particular soil and climatic conditions, the history of rye and wheat cultivation in the County of Uppland, Sweden, and the traditional knowledge involved, turned out to be sufficiently good reasons for the EU to grant the label. There are currently 3,207 products (European Commission, 2020b) in the GI scheme. The scheme grants three different types of labels that are printed on product packages: PDO, PGI and TSG (Figure 1).

The Protected Designation of Origin (PDO - left in Figure 1) is the most restricted label: "Every part of the production, processing and preparation process must take place in
Figure 1. PDO, PGI and TSG labels

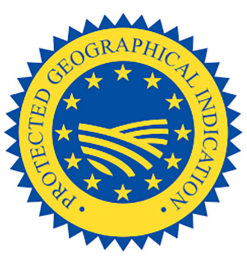

PGI

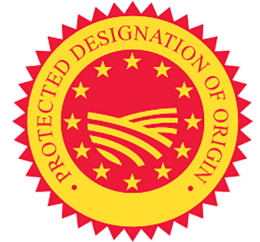

PDO

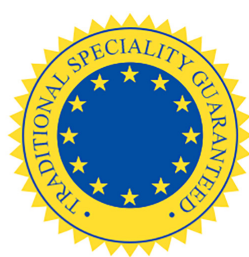

TSG 
the specific region" (European Commission, 2020a). The Protected Geographical Indication (PGI - in the middle of Figure 1) only demands that the features or reputation of the product are attributable to the geographic origin (London Economics, 2008) and is for products with "a particular quality, reputation or other characteristic that is essentially attributable to its geographical origin" (European Commission, 2020a).

The Traditional Speciality Guaranteed (TSG - right in Figure 1) is a related label, that "highlights the traditional aspects such as the way the product is made or its composition, without it being linked to a specific geographical area" (European Commission, 2020a). Because TSG is not linked to geographical origin it is not relevant for this paper.

National governments have an instrumental role in the establishment and development of GIs because they are responsible for examining the eligibility of applications by following the national objection procedure and reaching a decision concerning the formal registration of GIs (London Economics, 2008). When the product is registered, the government agencies enforce and check compliance with the PDO/PGI regulations. Several scholars (e.g. Profeta et al., 2010; Thiedig and Sylvander, 2000) consider the engagement of governments to be a key mechanism influencing the uneven distribution. Section 3 will consider this explanation, as well as others that are offered, in more detail.

The uneven spatial distribution of GIs over Europe can be seen clearly from Figure 2, which compares the sales value of GIs for each country of the EU. France and Italy clearly produce the most GI value, with more than 10 billion euros, while Northern and Eastern EU countries produce considerably less.

The uneven distribution also features in Table 1, which lists the registered GI applications per country for 2012 and 2020.

Section 4 returns to Table 1 and will delve more deeply into the uneven distribution.

\section{Legend}

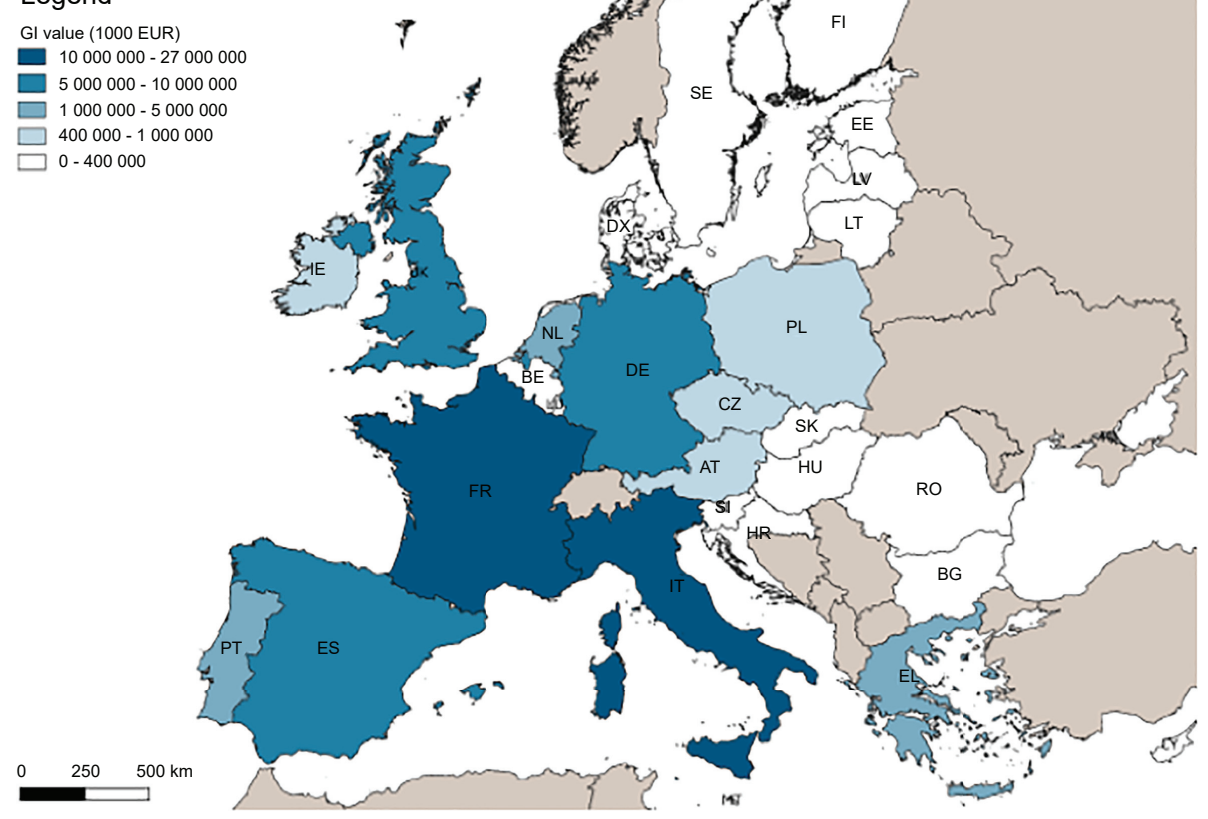

Source(s): Obtained from European Commission, 2020b, p. 17
Geographical indications unevenly distributed 
$\mathrm{BFJ}$

123,13

494

Table 1.

Registered applications by country 2012 and 2020

\begin{tabular}{|c|c|c|}
\hline & 2020 & 2012 \\
\hline Italy & 297 & 248 \\
\hline France & 249 & 192 \\
\hline Spain & 192 & 161 \\
\hline Portugal & 138 & 118 \\
\hline Greece & 104 & 97 \\
\hline Germany & 91 & 89 \\
\hline$U K$ & 69 & 46 \\
\hline Poland & 31 & 35 \\
\hline Crech Republic & 29 & 28 \\
\hline Croatia & 24 & 0 \\
\hline Slovenia & 22 & 16 \\
\hline Austria & 15 & 14 \\
\hline Belgium & 15 & 13 \\
\hline Hungary & 14 & 12 \\
\hline Slovakia & 12 & 10 \\
\hline the Netherlands & 11 & 9 \\
\hline Denmark & 8 & 5 \\
\hline Finland & 7 & 8 \\
\hline Ireland & 7 & 4 \\
\hline Lithuania & 7 & 2 \\
\hline Romania & 7 & 1 \\
\hline Sweden & 6 & 6 \\
\hline Cyprus & 5 & 2 \\
\hline Luxembourg & 4 & 4 \\
\hline Bulgaria & 3 & 1 \\
\hline Latvia & 3 & 0 \\
\hline Andorra & 1 & 0 \\
\hline
\end{tabular}

Note(s): Blocks represented by colour, South, North, Central East

\section{Theoretical framework}

The academic literature offers a range of possible explanations for the uneven distribution of GIs. Although studies on labelled regional products are based on a wide variety of approaches, theories, spatial scales and empirical material, three main explanations for the uneven spatial distribution of food labels recur, related to the causal influence of: (1) agricultural productivity, 
(2) government support, and (3) regional food cultures. Agricultural productivity arguments are often based on the idea that locational endowments (e.g. soil quality) affect productivity, which in turn affects the structure of the agricultural sector in specific regions. Government support highlights the important role of formal institutions and government involvement in regions, and their role in supporting GI applications. Arguments involving regional food cultures are based on the idea that the presence of a distinct food culture in a region can stimulate niche production and GI application.
Geographical indications unevenly distributed

\subsection{Agricultural productivity}

The agricultural productivity explanation focuses on the larger-scale political economic relations (Bowen, 2010) in which food items are produced and argues as follows. Industrialisation and modernisation processes in rural regions with productive potential resulted in homogenised food products, thereby dissolving the link between food and place (Parrot et al., 2002), and producing generic brands instead of place-related products. Parrott et al. (2002) argue that regions with suboptimal geographical conditions for farming are exempted from this trend. In these so-called Less Favoured Areas (LFAs) agricultural productivity is low due to poor soil composition, slopes, hedgerows, and other landscape barriers. As a result, agriculture in LFAs did not modernise quickly, which is why these areas often host a wide range of regional and unprocessed products (van der Ploeg and van Dijk, 1995; Parrot et al., 2002; Lee and Rund, 2003).

However, LFAs are neither a strong indicator of lagging agricultural modernisation nor of agricultural productivity, because what counts as LFA is not only determined by physical geographical features, but is also the result of a political process between the EU Member States over the allocation of funds and subsidies for rural development (see e.g. Rutz et al., 2014). Logically then, the link between LFAs and regional products is less straightforward than it is often presented in literature. Yet, because LFA features as a well-rehearsed explanation in literature and because the GI scheme has as an aim the support of LFA regions, an analysis of the link between the occurrence of GIs and LFA is included.

The argument that productive and modernised rural regions produce less GIs can be translated into several hypotheses that relate to agricultural productivity, size of the farm holdings, and the relative size of the region under consideration. First, the land productivity (added value per hectare) is understood to be higher in those regions that adopt modern farming practices (Matsuyama, 1992). Second, the average size of the farm holding differs substantially between modern and traditional agricultural areas, with modern areas featuring larger farms (Parrott et al., 2002; Goodman, 2004). Thirdly, LFAs are thought to have more GIs. Therefore, the larger the area designated as LFA, the more labelled products will occur (European Commission, 2010). Based on these ideas, the following hypotheses are postulated:

H1. The higher the agricultural productivity in a region, the lower its number of geographical indications.

H2. The larger the farm size in a region, the lower its number of geographical indications.

H3. The larger the area that is designated as LFA in a region, the higher its number of geographical indications.

\subsection{Government support}

Research points out that the role of government is substantial in all stages of the GI application. First, governmental agencies apply for the labels and are responsible for 
$\mathrm{BFJ}$

123,13

496

quality control (London Economics, 2008; Conneely and Mahon, 2015). Second, extensive human and institutional resources are required in the region, both to build effective organisations that produce and monitor labelled products, as well as for the application procedure itself (Bérard and Marchenay, 1995). However, the quality and quantity of government support differs greatly between countries, something that is perhaps attributable to different approaches to free trade (Barjolle and Sylvander, 2000; Moran, 1993b). As an illustration, in 2010 two government officials handled all applications in Germany, while France employed 250 officials in regional offices spread over the country (Profeta et al., 2010). Several authors single out government support before and during the application process as a crucial factor for explaining the uneven distribution of GIs (Thiedig and Sylvander, 2000; Ilbery and Kneafsey, 2000; Fragata et al., 2007; Profeta et al., 2010).

Aside from government involvement, historical legacies of food policies are also important. The existence of earlier schemes, like the Appellation d'Origine Contrôlée in France, is thought to have led to greater and better use of the current GI scheme. Several Southern European countries have a history of protecting regional products and are consequently familiar with such schemes (Moran, 1993b; Folkeson, 2005). In contrast, most Northern and Central Eastern European countries lack a tradition of, and familiarity with, protecting regional products (Anania and Nisticò, 2004; Dimara et al., 2004). Therefore, it is reasoned, these countries make less use of the GI scheme. Countries with earlier national protection schemes are France, Spain, Portugal and Italy. In the rest of Europe, Hungary and Germany had protection schemes but only for beverages, which according to the literature does not contribute to the capacity to successfully apply for PDO or PGI labels.

Although form and quality of governmental support are hard to parameterize, the "quantity" of government involvement can be approximated with agricultural subsidies. Moreover, the quality of government involvement is closely correlated to the quantity: countries that have had earlier schemes and provide more subsidies have, in general, a more elaborate and regionalised system of organisations that can facilitate the successful labelling of regional products. From these ideas the following hypotheses derive:

H4. The higher the agricultural subsidies provided to a region, the higher its number of geographical indications.

H5. Regions in countries which have had pre-EU labelling schemes will produce more geographical indications.

\subsection{Regional food cultures}

The final mechanism considered here is termed regional food culture; this is closely linked to the influence of earlier labelling schemes that was discussed in the previous section. Several studies have identified the importance of regional food cultures as a driver for labelling regional food (Ilbery and Kneafsey, 1999; Marsden et al., 2000; Murdoch et al., 2000; Parrott et al., 2002; Ilbery et al., 2004, 2005; Bérard et al., 2016). The main argument here is that regional products play a key role in Southern European but not in Northern European food cultures. Contrary to the Northern European countries, where scholars argue that "the regional distinctiveness of products and consumption habits were pulverised during the Industrial Revolution into placeless foodscapes” (Ilbery and Kneafsey, 2000, p. 319), regional food in Southern European countries continues to be traditionally and culturally significant through strong territorial linkages (Marsden et al., 2000; Tregear et al., 2007). The food cultures in Southern Europe thus help to sustain products from specific places, as there are 
both producers offering regional products, and consumers willing to pay for these products (Bérard and Marchenay, 1995).

Although the role of culture for food can hardly be overestimated, it is difficult to find indicators for regional food cultures. Two indicators, each with their respective hypothesis, are included in the analysis to probe the potential effect of the cultural-institutional context in which the production and consumption of GIs takes place. First, the analysis follows earlier approaches in literature that focus on differences in food cultures at country-level and expect that the more the consumption of agricultural goods resembles the production of the same goods, the more GIs will occur in regions of that country. Secondly, and tied to the need to include analyses of smaller spatial units (as presented in the introduction), an indicator for the regionality of a food culture is used. The hypothesis is that the more distinct a region's food culture is in respect to other regions, the more GIs will be present in a region. The reach of labels is used as an indicator for the distinctiveness of regional food culture. It is assumed that the fewer regions that share the same GI label, the more that label is indicative of a distinct regional food culture. These ideas are translated in the following hypotheses:

H6. The more similar the production and consumption of agricultural goods in a region, the higher the number of its geographical indications.

H7. The larger the area linked to a geographical indication, the lower the number of geographical indications in a region.

\section{First analysis}

The starting point for the analysis of the uneven distribution of GIs in Europe is to investigate the North/South divide identified in earlier studies. These studies consider France, Spain, Portugal, Italy, Greece, Malta and Cyprus as Southern European, while Sweden, Denmark, the UK, Finland, Germany, Austria, Netherlands, Belgium and Luxembourg are identified as Northern European Countries. More recent expansion of the $\mathrm{EU}$, with a group of countries termed here - in the spirit of the earlier division - the Central Eastern Bloc, has led to a considerable number of GIs granted in countries such as Poland and Czech Republic.

The Southern bloc also has most labels in absolute terms (see Table 1), and have filed the vast majority of registrations. In the first year of the scheme France, Italy, Spain, Portugal and Greece accounted for 281 of 336 products (83\%), and in 2020,985 "Southern" products were granted a GI from a total of 1,371 EU wide $(72 \%)$.

However, some internal differences within the North and South bloc in the number of GIs also exist. To illustrate, Northern countries such as Germany and the UK registered a significant number of labels, 91 and 69 respectively, while the remaining eight countries in the "North" have each at most 15 PDO/PGI labels. This raises the question whether dividing Europe into blocs of countries does justice to the internal differences that exist between the countries in each bloc?

A closer look at the differences and similarities between blocs and countries (Table 2) reveals that none of the three blocs displays a homogenous pattern of agricultural organisation, which was an important assumption in earlier studies to create the division into macro-regions (see Table 1 and argument in Parrott et al., 2002, p. 247). First, although most Northern European countries have a low percentage of agricultural workforce combined with a large average size of farm holding, "Northern" countries like Austria and the Netherlands deviate and have smaller holding sizes (Table 2). Second, the expansion of the EU with the "Central Eastern group" has further complicated the division in macroregions, as countries from this bloc can be found in nearly every category that is used to
Geographical indications unevenly distributed 
$\mathrm{BFJ}$ 123,13

\section{8}

characterise agricultural organisation. The Central Eastern bloc displays even larger internal differences, as it has both the largest (Czech Republic, 130 ha) and next-smallest holding size (Romania, 4 ha), and the highest workforce (Romania, 23\%) and next-lowest (Slovakia, 2\%) (see Appendix for additional tables). Third, a country from one bloc may resemble a country from another bloc more than a country from within the bloc it has been assigned to. Austria, Latvia and Spain, for example, are relatively similar according to the indicators used to characterise agricultural organisation, yet belong to different blocs. Finally, using the mean average as an indicator for divisions in blocs is unsatisfactory as it conceals heterogeneity within countries, e.g. the size of agricultural holdings varies greatly within Greece and Spain.

In summary, the organisation of the agro-food sector in Europe is far more complex than comparisons of countries in blocs reveals. Such comparisons hide the heterogeneity that exists between and within countries and can only yield ambiguous interpretations. Moreover, the country level is not the only aggregation relevant for the labelling of regional products. As such, there is a need to approach the labelling of regional products as a multi-level process. The next section describes this approach.
Table 2.

Workforce in agriculture and average size of holding in Europe, Eurostat, 2016 (most recent data available at the time of writing)

\begin{tabular}{|l|l|}
\hline In \% & Workforce in agriculture in \\
\hline$<5$ & Luxembourg \\
& UK \\
& Malta \\
& Belgium \\
& Sweden \\
& Germany \\
& Slovakia \\
& The Netherlands \\
& Denmark \\
& France \\
& Czech Republic \\
& Estionia \\
& Finland \\
& Austria \\
& Italy \\
& Spain \\
& Cyprus \\
& Ireland \\
& Latvia \\
& Hungary \\
& Croatia \\
\hline $5-10$ & Lithuania \\
& Slovenia \\
& Portugal \\
\hline $\mathbf{2 0}$ & Poland \\
& Greece \\
\hline $\mathbf{1 0 - 1 5}$ & Bulgaria \\
& Romania \\
\hline & \\
\hline
\end{tabular}




\begin{tabular}{|l|l|}
\hline In $h a$ & Average size of the bolding in \\
\hline$<\mathbf{1 0}$ & Malta \\
& Cyprus \\
& Romania \\
& Greece \\
& Slovenia \\
\hline $\mathbf{1 0 - 2 0}$ & Poland \\
& Hungary \\
& Italy \\
& Croatia \\
& Portugal \\
& Lithuania \\
\hline $\mathbf{2 0 - 3 0}$ & Austria \\
& Bulgaria \\
& Spain \\
& Latvia \\
\hline $\mathbf{3 0 - 4 0}$ & The Netherlands \\
& Ireland \\
& Belgium \\
\hline $\mathbf{4 0 - 7 0}$ & Finland \\
& Sweden \\
& Estonia \\
& Germany \\
& France \\
& Luxembourg \\
\hline $\mathbf{7 0}$ & Slovakia \\
& Denmark \\
& UK \\
& Czech Republic \\
\hline
\end{tabular}

Geographical indications unevenly distributed

Note(s): Blocks represented by colour, South, North, Table 2. Central East

\section{Methodology}

The methodology used to analyse the uneven distribution of labels in Europe as the outcome of a multi-level process is based on organisational ecology, an evolutionary approach (Hannan and Freeman, 1989; Hannan et al., 1995). This approach was developed to analyse how organisations and firms evolve, and is applied here to model the establishment of GI labels.

The statistical analysis is a negative binomial regression, because the dependent variable (number of new labels granted in region $i$ at time $t$ ) is a count variable (i.e. 1, 2, 3 etc.) instead of a continuous scale. A correction for an over-expression of zeros was needed, because most regions lack GIs. Using such a zero-inflated negative binomial regression also gives an analytical advantage: as a two-step estimation, it reflects the conceptual distinction between regional food and regional food labels. It does so in the following way: first, the logit part of the regression that is modelled separately (but not reported) identifies factors that influence whether or not products are able to obtain a label; second, the negative binomial part of the regression explains the variation 
$\mathrm{BFJ}$

123,13 of the non-zero values, or why particular regions are able to generate relatively more labels than other regions.

\subsection{Data}

The data used in this paper comprises all labels granted from 1996 to 2012, which amounts to a total of 1,138 protected products, of which 558 were registered as PDO and 542 as PGI. They were extracted from the EU database on GIs (DOOR database), which contains all pending and granted applications for PDO, PGI and TSG. All applications were organised in a panel data set with each case defined by NUTS 3 region $i i$ in time $t t$. The time frame of 1996-2012 is the result of data availability at the time when this analysis was performed (2013-2014). Although it would be preferable to include more recent data, the analysis is nevertheless valuable and relevant because of its novel methodology and significant results, which both contribute to the study of, and debate about, food labels and their contribution to rural development.

Next, the DOOR database was complemented with several other data sources, including the Farm Survey Structure (FSS) containing country-level data on agricultural land use, input consumption and the agro-food industry, and NUTS 3 statistics on agriculture and economic development from 2000, 2003, 2005, 2007 and 2010 - all derived from EUROSTAT. Furthermore, additional country-level statistics on agricultural production have been obtained from the Food and Agricultural Organisation (FAO).

\subsection{Variables}

The dependent variable in the analysis is the number of new labels granted in region $\ddot{i}$ at time $t t$. The region is identified as NUTS 3 as it is the smallest spatial entity on which data can be gathered in the EU, and NUTS 3 is the region targeted by the EU GI scheme. Nonetheless, regions vary greatly between countries in size, but also in cultural significance: in Denmark and Portugal, for instance, the NUTS 3 regions correspond poorly with culturally defined notions of the region, while in Spain and Italy they correspond much better. The $27 \mathrm{EU}$ Member States together comprise 1,298 NUTS 3 regions. These regions, combined with the number of labels registered in 1996, result in a total of 22,610 observations for the dataset. Regions in the new Member States were excluded for those years in which they were not a member of the EU, which resulted in a total of 20,068 observations that can be used for the analysis.

The independent variables will enter the analysis in three steps, and mostly reflect the structure of the theoretical framework. The first step (Model 1) starts with four variables that approximate the basic occurrence of labels: $N 3, N 3^{2}, N 1$ and $N 1^{2}$. N3 is calculated as the number of labels already granted in the region, where $N 3^{2}$ is the square term. Similarly, $N 1$ entails the number of labels successfully applied for in the respective countries and $N 1^{2}$ is the corresponding square term. Jointly, these variables explain the basic occurrence of GIs in region $i i$ at time $t t$. Model 1 further includes several control variables. The first is a dummy for observations made in 1996 (D_1996). A control for 1996 is necessary since there is an initial surge of new products registered in the database in the first year that is substantially greater than the number of labels registered in any other year. A second control (AREA) enters the model logtransformed and accounts for any effect due to the size of the region, which differs significantly within and between countries. A third control (POPULATION) is added for similar reasons and measures the number of inhabitants of region $i i$ at time $t t$ and also enters the equation in log-form. Finally, a fourth control variable is added as the regional per-capita income (N3_INCOME), also log-transformed. Subsequently, a set of 
control dummies is included for the different product-categories recognised under the PDO/PGI scheme.

The second step (Model 2) includes the first three variables as the proxy for agricultural productivity $(\mathrm{H} 1-\mathrm{H} 3)$ as follows. $\mathrm{H} 1$ is approximated by the productivity calculated as the total value added by the agricultural sector divided by the utilisable agricultural area (PRODUCTIVITY). H2 is tested by the average size of the holding in region $i$ at time $t$ in hectares (AVG_HOLDING). H3 is measured as the total area in a NUTS 3 region marked as Less Favoured Area (LFA), log-transformed.

The third step (Model 3) includes four variables to approximate both mechanisms of government support and regional food culture (H4-H7). The mechanisms are explained as separate effects, but because food culture is strongly related to, in particular, earlier food schemes they feature together in Model 3. H4 is represented by a dummy for regions that had previous schemes akin to the PDO/PGI scheme (SCHEME). The countries that previously had schemes overlap with the countries that are considered "South" in the literature on regional food. Therefore, the variable is twofold and is included to explore whether the arguments in the literature for the occurrence and distribution of labels - being located in "the South" and the effect of precious schemes having a positive effect - have any plausibility. H5 is represented by a variable in logform for the number of agricultural subsidies in euros per region (SUBSIDIES), to account for government support. H6 is accounted for in the variable NAT_CULTURE, which is measured as the correlation between production and consumption volumes of 120 different agricultural commodities on a yearly basis. Like the PRODUCTIVITY variable, this NAT_CULTURE variable is measured at the national level, which is consistent with existing literature. H7 is operationalised as follows. Each granted label has a number of regions in which it may be produced (the regional extent of a label). The smaller number of regions a label has, the more distinct the region's food culture is assumed to be. Regionality of food culture is therefore approximated by the average regional spread of the labels present in a region and enters the regression as REG_CULTURE. The statistical descriptions of the variables included are given in Table 3.

\begin{tabular}{lcccrr}
\hline Name & Scale $^{\mathrm{a}}$ & Min & Max & Mean & SD \\
\hline$\lambda_{\text {it }}{ }^{*}$ & 3 & 0 & 20 & 0.194 & 0.646 \\
$N 3$ & 3 & 0 & 37 & 1.819 & 2.815 \\
$N 3^{2}$ & 3 & 0 & 1,369 & 11.236 & 43.564 \\
$N 1$ & 1 & 0 & 239 & 50.060 & 49.133 \\
$N 1^{2}$ & 1 & 0 & 57,121 & 4919.969 & 8750.812 \\
PRODUCTIVITY** & 3 & -1.699 & 2.619 & 0.595 & 0.588 \\
HOLDING_SIZE & 2 & 0.322 & 273.920 & 44.198 & 54.262 \\
LFA** & 3 & 0 & 14.101 & 3.287 & 5.171 \\
SCHEME & 1 & 0 & 1 & 0.298 & 0.457 \\
SUBSIDIES** & 1 & -3.912 & 8.934 & 5.833 & 2.734 \\
NAT_CULTURE & 1 & 0.043 & 0.953 & 0.676 & 0.136 \\
REG_CULTURE & 3 & 0 & 96 & 7.237 & 1.407 \\
D_1996 & 3 & 0 & 1 & 0.054 & 0.226 \\
AREA** & 3 & 2.565 & 11.571 & 7.237 & 1.407 \\
INCOME** & 3 & 0.413 & 7.457 & 4.483 & 1.010 \\
POPULATION** & 3 & 1.988 & 9.940 & 5.503 & 0.891
\end{tabular}

Note(s): a: 1 = national level; $2=$ NUTS $2 ; 3$ = NUTS $3 ; *$ = dependent variable; standard deviation for dummies not reported; ** enters the model log-transformed
Geographical indications unevenly distributed

Table 3.

Variables included in the regression 
BFJ

123,13

502
Table 4.

Estimates of the negative binomial regressions

\section{Results}

As explained in Section 5.2 the independent variables are tested in three steps, i.e. three models. We discuss the results based on these steps and present what happens to the explanatory value of the variables when more variables are added. Table 4 reports the estimation on the full sample.

The most basic model, Model 1, demonstrates an initial absence of competition; the squared terms in this model are not significant. Instead, the competition between labels to be granted is generated through positive regional feedback (the more labels already granted in a region, the more new labels occur in that region) and negative national feedback (the more labels a country has, the fewer labels occur in the regions of that country).

Model 2 introduces the variables related to Agricultural Productivity, namely Productivity (H1), Holding size (H2) and LFA (H3). The results are only significant for Productivity, yet, contrary to what the literature assumes its effect is positive. Holding size and LFA are both insignificant.

Model 3 introduces the variables related to Government Support, namely Subsidies (H4) and Scheme (H5). The variables related to Regional Food Cultures are also introduced, namely National Culture (H6) and Regional Culture (H7). These additions change the picture. Discussing them from the top of the table down:

First, significant effects of competition are found: the national density $(N 1)$ and its squared term $\left(N 1^{2}\right)$ become negatively significant and best explain the difference between having labels or not (which is the zero-inflated part of the regression, not reported). Second, the results found in Model 2 about the significant role of Productivity (H1) for the number of labels in a country are not robust. Productivity becomes insignificant when Regional Food Cultures and Government Support are considered. Thus, in Model 3, none of the indicators for the mechanism of agricultural productivity are supported. Third, the scheme dummy in Model 3 is not significant either, suggesting that the distribution of labels cannot be explained

\begin{tabular}{|c|c|c|c|c|}
\hline & Variable & Model 1 & Model 2 & Model 3 \\
\hline & Constant & $-1.282^{* * *}(0.164)$ & $-1.487 * * *(0.230)$ & $-3.668 * * *(0.332)$ \\
\hline & $N 3$ & $0.055 * * *(0.013)$ & $0.054 * * *(0.013)$ & $0.047 * * *(0.013)$ \\
\hline & $N 3^{2}$ & $0.001(0.001)$ & $0.001 *(0.0005)$ & $0.001 * *(0.0005)$ \\
\hline & $N 1$ & $-0.006 * * *(0.001)$ & $-0.006 * * *(0.001)$ & $-0.010 * * *(0.002)$ \\
\hline & $N 1^{2}$ & $0.013^{*}(0.006)$ & $-0.010(0.006)$ & $-0.038 * * *(0.007)$ \\
\hline H1 & PRODUCTIVITY & & $0.248 * * *(0.054)$ & $0.005(0.059)$ \\
\hline $\mathrm{H} 2$ & HOLDING_SIZE & & $-0.0003(0.0006)$ & $-0.001(0.001)$ \\
\hline H3 & LFA & & $0.001(0.004)$ & $0.007(0.004)$ \\
\hline $\mathrm{H} 4$ & SUBSIDIES & & & $0.043 * * * *(0.011)$ \\
\hline H5 & SCHEME & & & $-0.015(0.097)$ \\
\hline H6 & NAT_CULTURE & & & $1.116^{* * * *}(0.238)$ \\
\hline \multirow[t]{10}{*}{$\mathrm{H} 7$} & REG_CULTURE & & & $0.016 * * *(0.001)$ \\
\hline & D_1996 & -0.307 *** $(0.085)$ & $-0.333^{* * * *}(0.086)$ & $-0.310 * * *(0.093)$ \\
\hline & AREA & $-0.015(0.019)$ & $0.016(0.025)$ & $0.070 * * *(0.025)$ \\
\hline & POPULATION & $-0.004(0.025)$ & $-0.021(0.028)$ & $0.078^{* * * *}(0.029)$ \\
\hline & INCOME & & $-0.025(0.013)$ & $0.007(0.015)$ \\
\hline & Prod.-group dummies & Yes & Yes & Yes \\
\hline & $A$ & $0.082^{* * * *}$ & $0.084^{* * * *}$ & $0.072^{* * * *}$ \\
\hline & $\rho$ & $0.362^{* * * *}$ & $0.365^{* * * *}$ & $0.368^{* * *}$ \\
\hline & AIC & 11625.89 & 11610.91 & 11312.88 \\
\hline & $N$ (non zero) & 2,635 & 2,635 & 2,635 \\
\hline
\end{tabular}

Note(s): *Significant at the $95 \%$ level; **Significant at the $99 \%$ level; ***Significant at the $99,9 \%$ level; Standard errors in parentheses 
well by a distinction between North and South based on previous schemes (H5). Fourth, the variables Subsidies (H4); National Culture (H6) and Regional Culture (H7) are highly significant, which indicates that subsidies and national and regional food culture correlate with the number of labels in a region.

\section{Discussion}

The first causal mechanism from the literature review is termed agricultural productivity. None of the three indicators - Productivity (H1), Holding size (H2) and LFA (H3) - proved significant. Based on the analysis, agricultural productivity thus seems to play a small role in the occurrence of GIs. Especially noteworthy is that the link between regional products and LFA does not seem to be significant. This link is a key assumption in literature and in EU policy (Vakoufaris, 2010; Borg and Gratzer, 2013; Tregear et al., 2007, 2015). Literature assumes that more regional products are produced in areas designated as LFA, which would therefore create better potential for establishment of GIs. Based on this idea, the EU believes that the GI scheme would mostly benefit LFA regions, as they should have more regional products. But the findings presented here suggest that the claim that establishment of GIs would support LFA is not warranted.

The second causal mechanism we singled out from the literature is government support. This mechanism consisted of two parts. First, current government support in the form of subsidies (H4), and second, earlier government support through previously established labelling schemes (H5). The analysis shows a high correlation between current government support and the occurrence of regional food labels. Our methods cannot determine the causal direction of this relationship - whether there is more support because there are more labels, or the other way around - but following the literature we think it is more likely that more support leads to more labels. A possible explanation for the effect of government support could be that with less support from the national organisation responsible for coordinating applications, there is less time and money for support available per potentially interested producer group. Surprisingly, the analysis shows that the more labels granted, the more labels will occur in that region. The explanation for this may be that experience with applications makes consecutive applications more efficient and effective through the accumulation of necessary resources and know-how at a regional level. Moreover, the more labels exist in a region, the more people (both producers and consumers) will know about the scheme. Therefore, other producers have more opportunities to learn about the possibility of applying for a label and may be more motivated to apply because a market already exists. The analysis also indicated that older labelling schemes do not lead to significantly more labels. This is a surprising finding as this indicator - older labelling schemes - both approximated earlier government support (that is often singled out as a key indicator) and is used to explain the prominence of Southern European countries in the establishment of the GIs (Sadílek, 2020; Albuquerque et al., 2018; Becker, 2009). These findings suggest that more subtle indicators of government support need to be considered instead, to explain the uneven distribution of GIs over Europe, as well as the role of other forms of support such as advertisement (Tarabella et al., 2021).

A third and last causal mechanism was regional food cultures. Finding a suitable indicator for culture is a challenge (Castelló et al., 2020). Two indicators were used that approximated food culture based on characteristics of the market for regional products and the distinctiveness of regional labels. The former indicator applied to the national level and measured the similarity between production and consumption patterns. The analysis demonstrated the significance of this indicator, suggesting that the more similarity exists between production and consumption, the more labels will occur. The latter indicator approximated the regionality of a food culture by looking at the average regional spread of
Geographical indications unevenly distributed 
BFJ

123,13

504

the labels present in a region. This variable was likewise highly significant. Taken together, these results suggest that more nuanced and detailed ideas of regionality and regional food cultures - rather than using Southern Europe (considering that the Scheme indicator H5 was not significant) as a shorthand for food culture - have more explanatory value for the uneven distribution of GIs in Europe.

The above offers two clear insights into the common explanations for the uneven distributions of GIs. First, the literature so far tends to equate regional food with regional food labels. Undeniably, the two are related - without regional food no regional food labels - yet the reverse does not necessarily hold as regional products can exist without labels. Less productive areas with low levels of modernised agriculture may perhaps explain the existence of regional food products, but not necessarily the labelling of these products. Likewise, government support during the application process could explain labelling, but is expected to have limited value for explaining the occurrence of regional food products. Second, most arguments so far are based on country-level comparisons. As the EU GI scheme targets regional levels, and because regional food labels relate to an even smaller spatial unit, country-level comparisons are not appropriate. Therefore, an analysis sensitive to data and mechanisms from smaller spatial units would be expected to have much higher explanatory power.

\section{Conclusion}

The uneven spatial distribution of GIs is easy to observe, but harder to explain. This paper critically examines earlier explanations and descriptions of EU regional food labelling. It does so by testing the strength of three common explanations, namely agricultural productivity, government support, and regional food cultures. The results clarify that plausible explanations need to take account of much more complexity than analyses hitherto have allowed for.

There is an important limitation of this study. The statistical analysis was performed in 2013/2014. This means that the data is relatively old. Does this impact the relevance of this paper? To date there has not been an equivalent study that can explain the occurrence of GIs in the detail that this paper offers. As such, the paper forms a relevant methodological contribution to the study of GIs. Yet, the article may be less topical if the situation has changed much since 2013/2014. Therefore, we assess how the dependent and independent variables have changed since then in the following. Table 1 gives an overview of the registered labels per Member State in 2012 and 2020 (the dependent variable). One noticeable change between 2012 and 2020 is that Croatia entered the EU in 2013 and went from 0 to 24 registered labels. Furthermore, there are some changes in the order of countries that have 10 or less registered labels, but these differences are slight. Interestingly, while many countries have been granted more labels since 2012, it is especially the countries who had the most in 2012, that also gained most between 2012 and 2020. All in all, the comparison of the situation in 2012 with 2020 demonstrates that the uneven distribution in 2012 is mirrored in 2020, with countries that have 10-300 labels listed in the same order as before. This means that the dependent variable, the uneven distribution, has not changed significantly between 2012 and 2020. Can the independent variables - GI scheme; LFA; holding size; productivity, subsidies, and food culture - have changed? It seems unlikely that significant changes occurred within a span of eight years for the GI scheme, the LFAs, the subsidies, as well as food culture. Holding size and productivity can be expected to have increased in all regions.

The analysis suggests that there is a need to distinguish between regional food on the one hand and regional food labels on the other. A considerable portion of the unexpected results of the analysis may be explained using this distinction. The production and marketing of regional food may indeed be associated with less intensive, less mechanised and less modernised agricultural production. As such, it would make sense to take e.g. 
agricultural productivity or the size of land holdings as indicators for areas where the chances are high that regional food products might become established. But these indicators are not sufficient to explain the occurrence and distribution of food labels. Such an explanation would require attention to the institutional legacies and opportunities that exist in these regions (Lucatelli, 2000; Belletti et al., 2017; Tarabella et al., 2019). Indeed, the GI scheme's aim of stimulating Less Favoured Areas (LFA) needs further scrutiny as there is no causal link between the occurrence of labels and these LFAs. While these areas may host many regional food products, they do not seem to be able to turn these products into labelled products. As discussed above, institutional legacies and opportunities may be an intervening factor here. Perhaps it is inherent for LFAs to have a lower level of services and support? As an explicit goal of the EU GI scheme is to support LFAs and a causal link between GIs and LFAs is lacking, a policy recommendation is to find out why this link is missing and see if the link can be strengthened. Here it is important to find out if this is because of a lack of services and support in LFAs. If this is the case then, increased support to LFAs may make the scheme more effective.

An important finding is that general ideas about the distinctiveness of food culture based on a North/South divide seem not to influence the distribution of labels, while the idea of regional food cultures based on market indicators (there are both producers offering labelled regional products, and consumers are interested in buying produce from their own countries) better explains the distribution of GIs.

Finally, the study leaves us with a little conundrum. The analysis highlights a positive feedback at a regional level between the number of GIs already established and the number of newly established labels, meaning that the presence of existing GIs makes new GIs in the same region more likely. But at national level the analysis shows a negative feedback: already established labels make occurrence of new labels less likely. More research is needed to explain why this feedback differs between regional and national levels.

\section{References}

Albuquerque, T.G., Oliveira, M.B.P. and Costa, H.S. (2018), "25 years of European Union (EU) quality schemes for agricultural products and foodstuffs across EU Member States", Journal of the Science of Food and Agriculture, Vol. 98, pp. 2475-2489.

Anania, G. and Nisticò, R. (2004), "Public regulation as a substitute for trust in quality food markets: what if the trust substitute can't be fully trusted?", Journal of Institutional and Theoretical Economics, Vol. 160, pp. 681-701.

Aprile, M.C., Caputo, V. and Nayga, R.M., Jr (2012), “Consumers' valuation of food quality labels: the case of the European geographic indication and organic farming labels", International Journal of Consumers Studies, Vol. 36, pp. 158-165.

Barham, E. (2003), "Translating terroir: the global challenge of French AOC labeling”, Journal of Rural Studies, Vol. 19, pp. 127-138.

Barjolle, D. and Sylvander, B. (2000), "Some factors of success for 'Origin Labelled Products' in agrifood supply chains in Europe: market, internal resources and institutions", INRA Actes et Communications, Vol. 17, pp. 45-71.

Becker, T.C. (2009), "European food quality policy: the importance of geographical indications, organic certification and food quality assurance schemes in European countries", Estey Journal of International Law and Trade Policy, Vol. 10, pp. 111-130.

Belletti, G., Marescotti, A. and Touzard, J.M. (2017), "Geographical indications, public goods, and sustainable development: the roles of actors' strategies and public policies”, World Development, Vol. 98, pp. 45-57.

Bérard, L. and Marchenay, P. (1995), "Lieux, temps et preuves: la construction sociale des produits de terroir", Terrain Revue d'ethnologie de l'Europe, Vol. 24, pp. 153-164.
Geographical indications unevenly distributed 
$\mathrm{BFJ}$

123,13

\section{6}

Bérard, L., Casabianca, F., Montel, M.C., Agabriel, C. and Bouche, R. (2016), "Salers Protected designation of origin cheese, France. The diversity and paradox of local knowledge in geographical indications", Culture and History Digital Journal, Vol. 5, pp. 1-14.

Bernabéu, R., Tendero, A. and Olmeda, M. (2011), "Consumer preferences versus commercial differentiation: a Spanish case study", British Food Journal, Vol. 114, pp. 1626-1639.

Bigelow, L., Carroll, G. and Seidel, M. (1997), "Legitimation, geographical scale and organizational density: regional patterns of foundings of American Automobile Producers, 1885-1981", Social Science Research, Vol. 26, pp. 277-398.

Bonadonna, A., Macar, L., Peira, G. and Giachino, C. (2017), "The dark side of the European quality schemes: the ambiguous life of the traditional specialities guaranteed", Calitatea, Vol. 18, pp. 102-108.

Borg, E.A. and Gratzer, K. (2013), "Collective brand strategy, entrepreneurship, and regional growth: the role of a Protected Designation of Origin (PDO)", Journal of World Economic Research, Vol. 2, pp. 26-38.

Bowen, S. (2010), "Embedding local places in global spaces: geographical indications as territorial development strategy", Rural Sociology, Vol. 75, pp. 209-243.

Bramley, C. and Kirsten, J. (2007), "Exploring the economic rationale for protecting geographical indications in agriculture", Agrekon: Agricultural Economics Research, Policy and Practice in Southern Africa, Vol. 46, pp. 47-71.

Castelló, E. (2020), "Storytelling in applications for the EU quality schemes for agricultural products and foodstuffs: place, origin and tradition", Spanish Journal of Agricultural Research, Vol. 18, pp. 1-12.

Cei, L., Defrancesco, E. and Stefani, G. (2018), "From geographical indications to rural development: a review of the economic effects of European Union policy", Sustainability, Vol. 10, pp. 1-21.

Chamorro, A., Rubio, S. and Miranda, F.J. (2015), "The region-of-origin (ROO) effect on purchasing preferences", British Food Journal, Vol. 117, pp. 820-839.

Condurso, C., Tripodi, G., Cincotta, F., Mazzaglia, A. and Verzera, A. (2016), "Analytical and sensory characterization of "Pesca di Leonforte", Journal of Essential Oil Research, Vol. 28, pp. 292-298.

Conneely, R. and Mahon, M. (2015), "Protected geographical indications: institutional roles in food systems governance and rural development", Geoforum, Vol. 60, pp. 14-21.

Dimara, E. and Skuras, D. (2005), "Consumer demand for informative labeling of quality food and drink products: a European Union case study", Journal of Consumer Marketing, Vol. 22, pp. 90-100.

Dimara, E., Petrou, A. and Skuras, D. (2004), "Agricultural policy for quality and producers' evaluations of quality market indicators: a Greek case study", Food Policy, Vol. 29, pp. 485-506.

Espejal, J., Fandos, C. and Flavian, C. (2008), "Consumer satisfaction. A key factor of consumer loyalty and buying intention of a PDO food products", British Food Journal, Vol. 110, pp. 865-881.

European Commission (1992), EC Regulation No. $2081 / 92$ on the Protection of Geographical Indications and Designations of Origin of Agricultural Products and Foodstuffs, European Commission, Brussels.

European Commission (2006), EC Regulation No. 510/2006 on the Protection of Geographical Indications and Designations of Origin for Agricultral Products and Foodstuffs, European Commission, Brussels.

European Commission (2010), "Impact assessment on geographical indications: accompanying document to the proposal for a regulation of the European parliament and of the council on agricultral product quality schemes", Commission Staff Working Paper, European Commission, Brussels.

European Commission (2012), "Quality schemes explained”, [online] available at: https://ec.europa.eu/ info/food-farming-fisheries/food-safety-and-quality/certification/quality-labels/quality-schemesexplained_en (accessed 10 January 2021). 
European Commission (2014), Official Journal European Union, European Commission, Brussels, [online] available at: https://eur-lex.europa.eu/legal-content/EN/ALL/?uri=CELEX\% 3A52014XC0318\%2801\%2918.3.2014 (accessed 10 January 2021).

European Commission (2020a), "Quality schemes explained", European Commission, Brussels, [online], available at: https://ec.europa.eu/info/food-farming-fisheries/food-safety-andquality/certification/quality-labels/quality-schemes-explained_en\#pgi (accessed 10 January 2021).

European Commission (2020b), Study on Economic Value of EU Quality Schemes, Geographical Indications (GIs) and Traditional Specialties Guaranteed (TSGs), European Commission, Brussel, [online], available at: https:/op.europa.eu/sv/publication-detail//publication/a72817947ebe-11ea-aea8-01aa75ed71a1 (accessed 10 September 2020).

Falguera, V., Aliguer, N. and Falguera, M. (2012), "An integrated approach to current trends in food consumption: moving toward functional and organic products?”, Food Control, Vol. 26, pp. 274-281.

Fandos, C. and Flavian, C. (2006), "Intrinsic and extrinsic quality attributes, loyalty and buying intention: an analysis for a PDO product", British Food Journal, Vol. 108, pp. 646-662.

Folkeson, C. (2005), Geographical Indications and Rural Development in the EU, Lund University, Lund.

Fragata, A., Tibério, M. and Teixeira, M. (2007), "Traditional products with protected designation of origin: policy and market situation in Portugal", New Medit, Vol. 6, pp. 4-12.

Goodman, D. (2004), "Rural Europe redux? Reflections on alternative agro-food networks and paradigm change", Sociologia Ruralis, Vol. 44, pp. 3-16.

Gracia, A. and de-Magistris, T. (2016), “Consumer preferences for food labeling: what ranks first?", Food Control, Vol. 61, pp. 39-46.

Grunert, K.G. and Aachmann, K. (2016), "Consumer reactions to the use of EU quality labels on food products: a review of the literature", Food Control, Vol. 59, pp. 178-187.

Hannan, M. and Freeman, J. (1989), Organizational Ecology, Harvard University Press, Cambridge, MA.

Hannan, M., Carroll, G., Dundon, E. and Torres, J. (1995), "Organizational evolution in a multinational context: entries of automobile manufacturers in Belgium, Britian, France, Germany and Italy", American Sociological Review, Vol. 60, pp. 509-528.

Ilbery, B. and Kneafsey, M. (1999), "Niche markets and regional speciality food products in Europe: towards a research agenda", Environment and Planning A, Vol. 31, pp. 2207-2222.

Ilbery, B. and Kneafsey, M. (2000), "Registering regional speciality food and drink products in the United Kingdom: the case of PDOs and PGIs", Area, Vol. 32, pp. 317-325.

Ilbery, B., Maye, D., Kneafsey, M., Jenkins, T. and Walkey, C. (2004), "Forecasting food supply chain developments in lagging rural regions: evidence from the UK", Journal of Rural Studies, Vol. 20, pp. 331-344.

Ilbery, B., Morris, C., Buller, H., Maye, D. and Kneafsey, M. (2005), "Product, process and place: an examination of food marketing and labelling schemes in Europe and North America", European Urban and Regional Studies, Vol. 12, pp. 116-132.

Ipsos- London Economics EAHC (2013), "Consumer market study on the functioning of voluntary food labeling schemes for consumers in the European Union", available at: http://collections. internetmemory.org/haeu/20171123130248/http://ec.europa.eu/consumers/consumer_evidence/ market_studies/food_labelling/docs/!nal_report_food_labelling_scheme_full_en.pdf (accessed 29 April 2020).

Joosse, S. (2014), Is it Local?: A Study About the Social Production of Local and Regional Foods and Goods, Doctoral dissertation, Department for Social and Economic Geography, Uppsala University.

Josling, T. (2006), "The war on Terroir: geographical indications as Transatlantic trade conflict", Journal of Agricultural Economics, Vol. 57, pp. 337-363.

Geographical indications unevenly distributed 
$\mathrm{BFJ}$

123,13

\section{8}

Krystallis, A. and Ness, M. (2005), "Consumer preferences for quality foods from a South European perspective: a conjoint analysis implementation on Greek olive oil”, International Food and Agribusiness Management Review, Vol. 8, pp. 62-91.

Krystallis, A., Chrysochou, P., Perrea, T. and Tzagarakis, N. (2017), "A retrospective view on designation of origin labeled foods in Europe", Journal of International Food and Agribusiness Marketing, Vol. 29, pp. 217-233.

Lee, J. and Rund, B. (2003), EU-protected Geographical Indications: An Analysis of 603 Cases, Proyecto GIANT American University, Washington, DC.

Likoudis, Z., Sdrali, D., Costarelli, V. and Apostolopoulos, C. (2016), "Consumers' intention to buy protected designation of origin and protected geographical indication foodstuffs: the case of Greece", International Journal of Consumer Studies, Vol. 40, pp. 283-289.

London Economics (2008), Evaluation of the CAP-Policy on Protected Designations of Origin (PDO) and Protected Geographical Indications (PGI), London Economics, London.

Lucatelli, S. (2000), Appellations of Origin and Geographical Indications in OECD Member Countries: Economic and Legal Implications, OECD, Paris.

Marcoz, E.M., Melewar, T.C. and Dennis, C. (2016), "The value of region of origin, producer and protected designation of origin label for visitors and locals: the case of fontina cheese in Italy", International Journal of Tourism Research, Vol. 18, pp. 236-250.

Marsden, T., Banks, J. and Bristow, G. (2000), "Food supply chain approaches: exploring their role in rural development”, Sociologia Ruralis, Vol. 40, pp. 424-439.

Matsuyama, K. (1992), "Agricultural productivity, comparative advantage and economic growth", Journal of Economic Theory, Vol. 58, pp. 317-334.

Moran, W. (1993a), "The wine appellation as territory in France and California", Annals of the Association of American Geographers, Vol. 83, pp. 694-737.

Moran, W. (1993b), "Rural space as intellectual property”, Political Geography, Vol. 12, pp. 263-277.

Murdoch, J., Marsden, T. and Banks, J. (2000), "Quality, nature, and embeddedness: some theoretical considerations in the context of the food sector", Economic Geography, Vol. 76 No. 2, pp. 107-125.

Parrott, N., Wilson, N. and Murdoch, J. (2002), "Spatializing quality: regional protection and the alternative geography of food", European Urban and Regional Studies, Vol. 9, pp. 241-261.

Profeta, A., Balling, R., Schoene, V. and Wirsig, A. (2010), "Protected geographical indications and designations of origins: an overview of the status quo and the development of the use of regulation (EC)510/06 in Europe, with special consideration of the German situation", Journal of International Food and Agribusiness Marketing, Vol. 22, pp. 179-198.

Quiñones Ruiz, X.F.Q., Forster, H., Penker, M., Belletti, G., Marescotti, A., Scaramuzzi, S., Broscha, K., Braito, M. and Altenbuchner, C. (2018), "How are food Geographical Indications evolving?-An analysis of EU GI amendments", British Food Journal, Vol. 120, pp. 1876-1887.

Rutz, C., Dwyer, J. and Schramek, J. (2014), "More new wine in the same old bottles? The evolving nature of the CAP reform debate in Europe, and prospects for the future", Sociologica Ruralis, Vol. 54, pp. 266-284.

Sadílek, T. (2020), "Utilization of food quality labels included in the European Union quality schemes", International Journal on Food System Dynamics, Vol. 11, pp. 72-83.

Sellers-Rubio, R. and Más-Ruiz, F.J. (2015), "Economic efficiency of members of protected designations of origin: sharing reputation indicators in the experience goods of wine and cheese", Review of Managerial Science, Vol. 9, pp. 175-196.

Tarabella, A., Varese, E. and Cesarani, M.C. (2019), "EU voluntary certification schemes for agricultural products and foodstuffs", in Tarabella, A. (Ed.), Food Products Evolution: Innovation Drivers and Market Trends, Springer, Zürich, pp. 59-77. 
Tarabella, A., Apicella, A., Tessitore, S. and Romano, M.F. (2021), "The effects of advertisements on consumer choices and health: a content analysis of health claims in Italian magazines", British Food Journal, available at: https://www.emerald.com/insight/0007-070X.htm.

Tessitore, S., Iraldo, F., Apicella, A.A. and Tarabella, A.T. (2020), "The link between food traceability and food labels in the perception of young consumers in Italy", International Journal on Food System Dynamics, Vol. 11, pp. 425-440.

Teuber, R. (2011), “Consumers' and producers' expectations towards geographical indications”, British Food Journal, Vol. 113, pp. 900-918.

Thiedig, F. and Sylvander, B. (2000), "Welcome to the club?: an economical approach to geographical indications in the European Union", Agrarwirtschaft, Vol. 49, pp. 428-437.

Tregear, A., Arfini, F., Belletti, G. and Marescotti, A. (2007), "Regional foods and rural development: the role of product qualification”, Journal of Rural Studies, Vol. 23, pp. 12-22.

Tregear, A., Torök, Á. and Gorton, M. (2015), "Geographical indications and upgrading of smallscale producers in global agro-food chains: a case study of the Makó Onion Protected Designation of Origin”, Environment and Planning A, Vol. 48, pp. 433-451.

Trubek, A. (2008), The Taste of a Place: A Cultural Journey into Terroir, University of California Press, Berkeley and Los Angeles.

Trubek, A. and Bowen, S. (2008), "Creating the taste of place in the United States: can we learn from the French?", GeoJournal, Vol. 73, pp. 23-30.

Vakoufaris, H. (2010), "The impact of Ladotyri Mytilinis PDO cheese on the rural development of Lesvos island, Greece", Local Environment, Vol. 15, pp. 27-41.

van der Ploeg, J.D. and van Dijk, G. (1995), Beyond Modernization. The Impact of Endogenous Rural Development, van Gorcum, Assen.

Wenting, R. and Frenken, K. (2011), "Firm entry and institutional lock-in: an organizational ecology analysis of the global fashion design industry", Industrial and Corporate Change, Vol. 20, pp. 1031-1048.

\section{Appendix}

\section{Modelling framework}

In its most basic form, the equation to estimate is as follows (Hannan and Freeman, 1989):

$$
\lambda_{i t}=\alpha+\beta_{1 t} n 3+\beta_{2 t} n 3^{2}+\varepsilon \lambda_{i t}=\alpha+\beta_{1 t} n 3+\beta_{2 t} n 3^{2}+\varepsilon
$$

where $n 3$ is the number of labels already granted in a region and $n 3^{2}$ its squared term. Such a model can be extended to account for multiple levels of geographical aggregation (Bigelow et al., 1997; Wenting and Frenken, 2011). The influence of national governments in the application procedure makes it important to consider such extension to multiple scales. Consequently, the model becomes:

$$
\begin{aligned}
& \lambda_{i t}=\alpha+\beta_{1 t} n 3+\beta_{2 t} n 3^{2}+\beta_{3 t} N 1+\beta_{4 t} N 1^{2}+\ldots \beta_{i t} x_{i t}+\varepsilon \\
& \lambda_{i t}=\alpha+\beta_{1 t} n 3+\beta_{2 t} n 3^{2}+\beta_{3 t} N 1+\beta_{4 t} N 1^{2}+\ldots \beta_{i t} x_{i t}+\varepsilon
\end{aligned}
$$

with $N 1$ being the national density of labels, $N 1^{2}$ its squared term and $x_{i}$ being a vector of additional covariates. Combined, these variables model the occurrence of new regional food labels as a function of regional and national density - approximating regional and national competition by its squared term.

A final addition to the modification of the original model (Bigelow et al., 1997) concerns a correction for first-order spatial autocorrelation that is a problem inherent to the PDO-PGI case. Most labelled products are produced in multiple neighbouring NUTS 3 regions. Therefore, the number of labels in the neighbouring regions is the most important explanatory variable for the number of labels in the region observed - simply because it is the same product. To account for the resulting autocorrelation, the final model is estimated as follows: 
$\mathrm{BFJ}$

123,13

$$
\begin{aligned}
& \lambda_{i t}=\alpha+\beta_{1 t} n 3+\beta_{2 t} n 3^{2}+\beta_{3 t} N 1+\beta_{4 t} N 1^{2}+\ldots \beta_{i t} x_{i t}+\rho W \lambda_{j t}+\varepsilon \\
& \lambda_{i t}=\alpha+\beta_{1 t} n 3+\beta_{2 t} n 3^{2}+\beta_{3 t} N 1+\beta_{4 t} N 1^{2}+\ldots \beta_{i t} x_{i t}+\rho W \lambda_{j t}+\varepsilon
\end{aligned}
$$

where the additional $\rho$ is the spatial autocorrelation coefficient to be estimated, $W$ is the rowstandardised adjacency matrix and $\lambda_{j t}$ is the dependent variable at the other regions $j$ at time $t$. Regions are adjacent (indicated as 1 in matrix $W$ ) if they have shared borders but are located in the same country since to date no multi-country PDO/PGI labels have been granted.

\section{Corresponding author}

Sofie Joosse can be contacted at: sofie.joosse@slu.se

For instructions on how to order reprints of this article, please visit our website: www.emeraldgrouppublishing.com/licensing/reprints.htm Or contact us for further details: permissions@emeraldinsight.com 